\title{
Penentuan momen inersia benda silinder pejal dengan integral dan tracker
}

\author{
Muhammad Minan Chusni ${ }^{1}$, Muhammad Ferdinan Rizaldi ${ }^{1}$, Santi Nurlaela ${ }^{1}$, Siti \\ Nursetia $^{1}$, Wawat Susilawati ${ }^{1}$ \\ ${ }^{1}$ Pendidikan Fisika, UIN Sunan Gunung Djati Bandung, Kota Bandung 40614, Indonesia \\ E-mail: minan.chusni@uinsgd.ac.id; ferdinanrizaldi2613@gmail.com; \\ santi.nurlaela19@gmail.com; nursetiasiti1234@gmail.com; susilawatiwawat18@gmail.com
}

Received: 1101 2018. Revision: 2203 2018. Accepted: 30032018

\begin{abstract}
Abstrak
Telah dilakukan eksperimen mengenai penentuan nilai momen inersia dari silinder pejal. Penelitian ini bertujuan untuk membandingkan nilai momen inersia dengan variasi jari-jari. Eksperimen ini dilakukan dengan metode membandingkan hasil pengolahan data tracker dan teknik integral. Teknik integral didasarkan pada teorema sumbu sejajar yang mengintegralkan jari-jari terhadap massa benda, jari-jari di bedakan dengan tiga variasi benda. Dari eksperimen

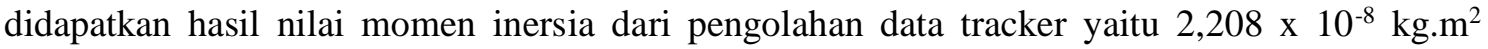
dengan jari-jari $2,4 \times 10^{-3} \mathrm{~m}, 3,02 \times 10^{-7} \mathrm{~kg} \cdot \mathrm{m}^{2}$ dengan jari-jari $3,7 \times 10^{-3} \mathrm{~m}, 5,25 \times 10^{-6} \mathrm{~kg} \cdot \mathrm{m}^{2}$ dengan jari-jari $5,6 \times 10^{-3} \mathrm{~m}$. Sedangkan secara perhitungan menggunakan teknik integral yaitu 2,209 × $10^{-8} \mathrm{~kg} \cdot \mathrm{m}^{2}$ dengan jari-jari $2,4 \times 10^{-3} \mathrm{~m}, 2,754 \times 10^{-7} \mathrm{~kg} \cdot \mathrm{m}^{2}$ dengan jari-jari $3,7 \times 10^{-3} \mathrm{~m}$, $5,25 \times 10^{-6} \mathrm{~kg} \cdot \mathrm{m}^{2}$ dengan jari-jari $5,6 \times 10^{-3} \mathrm{~m}$.
\end{abstract}

Kata Kunci: integral; momen inersia; tracker

\section{Measurement of inertial cylinder inertia moment with integral and tracker}

\begin{abstract}
Experiments have been conducted on determining the value of moment inertia from solid cylinders. This study aims to compare the value of moment inertia with variations of radius. This experiment was conducted by comparing the results of data tracker processing and integral technique of moment of inertia. The integral technique is based on a parallel axis theorem that integrates the radius to the mass of the body, the radius distinguishes by three variations of the object. From the experiments obtained the value of the moment of inertia of the

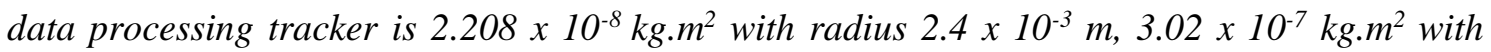
radius $3.7 \times 10^{-3} \mathrm{~m}, 5.25 \times 10-6 \mathrm{~kg} . \mathrm{m}^{2}$ with radius of $5.6 \times 10-3 \mathrm{~m}$. While calculation using integral technique that is 2,209 $\times 10^{-8} \mathrm{~kg} \cdot \mathrm{m}^{2}$ with radius $2,4 \times 10^{-3} \mathrm{~m}, 2,754 \times 10^{-7} \mathrm{~kg} \cdot \mathrm{m}^{2}$ with radius $3,7 \times 10^{-3} \mathrm{~m}, 5,25 \times 10^{-6} \mathrm{~kg} \cdot \mathrm{m}^{2}$ with radius of $5.6 \times 10^{-3} \mathrm{~m}$.
\end{abstract}

Keywords: integral; inertia moment; tracker

\section{PENDAHULUAN}

Fisika sebagai ilmu merupakan produk yang menghasilkan ketetapan, postulat, konsep, hukum dan teori. Fisika pun dapat dipandang sebagai sebuah proses, oleh karena itu produk-produk dari fisika didapatkan dari proses ilmiah yang meliputi, pengamatan, dugaan/ hipotesis, penelitian/ eksperimen, penarikan kesimpulan, dan juga publikasi (Yusuf, 2015).

Salah satu proses penting dalam fisika adalah eksperimen, karena fisika didasarkan pada gejala-gejala fisis yang dapat dijelaskan melalui observasi dan eksperimen yang dilakukan. Terdapat banyak cara untuk melakukan eksperimen, salah satunya adalah 
Jurnal Pendidikan Fisika dan Keilmuan, 4 (1), 2018 - 43

Muhammad Minan Chusni, Muhammad Ferdinan Rizaldi, Santi Nurlaela, Siti Nursetia, Wawat Susilawati

dengan pengukuran dalam praktikum (Rivia, 2016).

Diantara tujuan dari ilmu fisika adalah mempelajari gerak objek baik itu benda atau makhluk hidup. Gerak mempunyai sifat umum yang dapat diklasifikasikan sebagai kinematik, sifat umum itu berupa asumsi bahwa gerak hanya berada disepanjang garis lurus baik vertikal, horizontal maupun miring. Objek bergerak dapat berupa partikel dan setiap bagian bergerak dalam arah dan kecepatan yang sama (Halliday, Resnick, \& Walker, 2010).

Gerak terbagi menjadi dua berdasarkan kecepatan yang terjadi pada benda yaitu, gerak rotasi dan gerak translasi (Tristiono, 2011). Penerapan terpenting dari kedua gerak ini adalah gerak menggelinding pada roda ataupun objek seperti roda, dimana semua titik pada roda bergerak dengan laju sudut $\omega$ yang sama. (Halliday, Resnick, \& Walker, 2010)

Gerak rotasi dan translasi tidak dapat dipisahkan dari momen inersia. Hal ini dikarenakan, momen inersia adalah besaran turunan yang dipengaruhi oleh jari-jari suatu benda. Apabila suatu benda memiliki jari-jari maka benda tersebut akan memiliki kecepatan sudut dan membuatnya berotasi (Riswanto, 2014; Jumini, 2013).

Momen inersia adalah ukuran kelembaman suatu benda untuk berotasi pada porosnya, momen inersia juga disebut sebagai besaran pada gerak rotasi yang analog dengan massa pada gerak translasi (Banjarnahor, 2012; Zhang, 2014).
Jika momen inersia besar maka benda akan sulit untuk melakukan perputaran dari keadaan diam dan semakin sulit berhenti ketika dalam keadaan berotasi, itu sebabnya momen inersia juga disebut sebagai momen rotasi (Rivia, 2016). Setiap benda tegar bergerak melingkar di masing-masing titik partikel geraknya, hal ini merupakan acuan tertentu yang dapat ditentukan dengan momen inersia (Sahala S., 2013). Besar momen inersia pada silinder pejal dapat dicari dengan persamaan 1 :

$$
I=k M R^{2}
$$

Dimana : $I$ adalah momen inersia $\left(\mathrm{kg} \cdot \mathrm{m}^{2}\right), k$ merupakan konstanta dari bentuk benda, $m$ adalah massa benda $(\mathrm{kg})$ dan $R^{2}$ merupakan kuadrat dari jari-jari benda $\left(\mathrm{m}^{2}\right)$ (Hajderi, 2012).

Momen inersia pada suatu benda tegar dapat ditentukan massa dan dimensi fisiknya, baik dengan cara matematis maupun eksperimen. Metode eksperimen dapat dilakukan sebagai pembuktian sebuah konsep mengenai momen inersia, besaran-besaran yang terukur dan yang mempengaruhi nilai momen inersia (Hara, 2012).

Momen inersia dipengaruhi oleh jarijari (jarak benda dari sumbu). Benda yang berbentuk sama namun momen inersianya bisa saja berbeda karena pengaruh jari-jari. Semakin besar jari-jari benda maka semakin besar momen inersianya (Tipler, 1998). Hal ini didasarkan pada silinder pejal yang tidak memiliki rongga, sehingga jari-jari yang dimiliki utuh (Zafar, 2012), sebagaimana ditunjukkan pada gambar 1 .

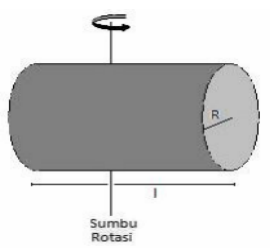

Gambar 1. Silinder pejal

Silinder pejal tanpa rongga memiliki konstanta yang sama dengan silinder pejal berongga yaitu $1 / 2$, akantetapi berbeda dari jari-jari. Silinder pejal hanya memiliki 1 besar jari-jari, tanpa jari-jari dalam (Giancoli, 2013).

Teorema sumbu sejajar yang menyatakan bahwa momen kelembaman benda terhadap sumbu yang sejajar dengan sumbu yang melalui titik pusat masa pada benda tegar (Kuntoro P. \& Murdaka Eka J.,
2009). Teorema ini menyatakan hasil nilai dengan momen inersia benda terhadap sumbu melalui titik pusat massanya ditambah dengan hasil kali antara massa bendadengan jarak kuadrat dari kedua yang sejajar itu (Mochlas, 2016). Mengacu pada teorema tersebut momen inersia dapat dibuktikan dalam teknik integral dengan mengintegralkan jari-jari terhadap massa benda (Krishnan, 2016). 
Penerapannya dalam pendidikan, seperti di pelajaran fisika terdapat kompetensi untuk menentukan momen inersia. Materi tersebut dibahas lebih secara mendalam mengenai benda tegar, karena bentuknya yang beraturan sehingga mudah ditentukan. Permasalahan yang terjadi pada kebanyakan peserta didik adalah tidak mudahnya dalam membedakan konstanta dan kurangnya pemahaman konsep terhadap momen inersia.

Untuk menentukan nilai momen inersia dan termasuk faktor-faktor yang mempengaruhi benda ketika menggelinding dapat diketahui dari pengolahan tinjauan gerak benda. Namun gerak benda tersebut harus konstan, hal ini bertujuan agar data yang dihasilkan mempunyai tingkat akurat dan ketelitian yang tinggi (Setyawan, 2017).

Eksperimen gerak menggelinding pada silinder pejal pada bidang miring dibantu olahan data dalam sebuah aplikasi Tracker. Penggunaan aplikasi Traker berfungsi untuk dapat menggetahui perubahan kecepatan benda setiap saat (Juansyah, 2015). Penelitian ini bertujuan untuk menentukan momen inersia pada gerak menggelinding silinder pejal dengan perhitungan integral dan dengan bantuan aplikasi Tracker.

\section{METODE}

Penelitian ini menggunakan pendekatan eksperimen langsung berbantukan aplikasi Tracker. Hasil pengukuran momen inersia dengan bantuan apliaksi Tracker dibandingkan degnan perhitungan secara langsung menggunakan teknik integral.

Penelitian ini dilakukan di laboratorium Pendidikan Fisika UIN Sunan Gunung Djati Bandung pada bulan Oktober 2017.Subjek penelitian yang diteliti berupa silinder pejal dengan variasi jari-jari yaitu 2,4 x 10-3 m, 3,7 x 10-3 m dan 5,6 x 10-3 m. Adapun ketiga subjek peneltian ini dapat dilihat pada gambar 2 .

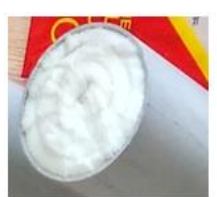

Silinder 1

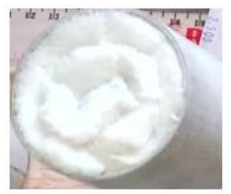

Silinder 2

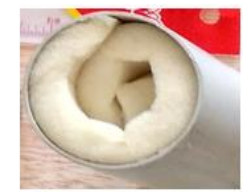

Silinder 3.

Gambar 2. Subjek penelitian

Prosedur penelitian ini adalah sebagai berikut:

1. Mengukur diameter tiap-tiap silinder pejal menggunakan jangka sorong.

2. Mengukur massa tiap-tiap silinder pejal menggunakan neraca digital (massa di buat tetap sebesar $76,7 \times 10^{-3} \mathrm{~kg}$ ).

3. Menyusun rangkaian eksperimen.

4. Mengambil video dari silinder pejal yang menggelinding di papan miring sampai silinder pejal berhenti sepanjang lantai yang kita anggap sebagai sumbu $\mathrm{x}$.

5. Mengolah video menggunakan aplikasi Tracker untuk mendapatkan nilai dari waktu yang diperlukan selama rotasi di sumbu $\mathrm{x}$, posisi benda pada sumbu $\mathrm{x}$, kecepatan linier terhadap sumbu $\mathrm{x}$, dan percepatan linier terhadap sumbu $\mathrm{x}$.

Data yang diperoleh dari penelitian ini adalah massa silinder pejal yang dibuat tetap, jari-jari silinder pejal, posisi, waktu, kecepatan dan percepatan silinder saat menggelinding yang didapat dati aplikasi Tracker.

Instrumen pengambilan data yang digunakan dalam penelitian ini adalah:

1. Papan sepanjang 1 meter, sebagai bidang untuk menggelinding benda

2. Penyangga papan, sebagai pengatur kemiringan benda

3. Tiga buah silinder pejal berbeda ukuran jari-jari namun bermassa sama, sebagai objek yang diteliti

4. Kamera, untuk merekam proses eksperimen dan sebagai bahan untuk proses track

5. Jangka sorong, untuk mengukur diameter benda

6. Neraca, untuk mengukur massa benda

Teknik pengumpulan data dilakukan dengan dua metode yaitu dengan persamaan umum momen inersia berbantukan aplikasi 
Jurnal Pendidikan Fisika dan Keilmuan, 4 (1), 2018 - 45

Muhammad Minan Chusni, Muhammad Ferdinan Rizaldi, Santi Nurlaela, Siti Nursetia, Wawat Susilawati

Tracker dan integral momen inersia dalam teorema sumbu sejajar.

HASIL DAN PEMBAHASAN
Data hasil pengukuran momen inersia dengan variasi jari-jari pada silinder pejal menggunakan aplikasi Tracker sebagaimana disajikan pada Tabel 1 berikut.

Tabel 1. Data hasil tracker silinder pejal

\begin{tabular}{ccccc}
\hline No. & Jari-jari $(\mathbf{m})$ & $\mathbf{d r}(\mathbf{m})$ & $\mathbf{d t}(\mathbf{s})$ & $\mathbf{v}(\mathbf{m} / \mathbf{s})$ \\
\hline 1 & $2,4 \times 10^{-3}$ & $1,54 \times 10^{-2}$ & 1,53 & $1,01 \times 10^{-2}$ \\
\hline 2 & $3,7 \times 10^{-3}$ & 1,46 & 1,53 & 0,95 \\
\hline 3 & $5,6 \times 10^{-3}$ & 1,44 & 1,70 & 0,85 \\
\hline
\end{tabular}

Data tracker diolah dengan menggunakan persamaan 1, dengan mensubtitusikan jari-jari pada persamaan tersebut. Data $d r$ adalah rata-rata jarak yang dihasilkan tiap tiap satu klik track pergerakannya. Satu klik track menghasilkan waktu yang berbeda beda $(d t)$. Dari data Tracker juga diambil kecepatan tiap satu klik track, kemudian dirata-ratakan dan menghasilkan kecepatan rata-rata tiap $d t$ dan $d r$ yang diperoleh. Kecepatan yang dihasilkan tiap track tidak konstan, hal ini dikarenakan gerak menggelinding pada bidang miring mempercepat laju benda. Hal ini berlaku gerak translasi pada silinder pejal dengan persamaan umum $E K_{\text {translasi }}=\frac{1}{2} m v^{2}$, sehingga membuktikan teori yang menyatakan bahwa kecepatan mewakili gerak translasi silinder pejal (Riswanto, 2014).

Dari hasil pengolahan data yang didasarkan pada persamaan 1 , dengan massa sebagai variabel tetap sebesar $76,7 \times 10^{-3} \mathrm{~kg}$. Hasil pengolahan data Tracker menghasilkan momen inersia yang di bandingkan dengan momen inersia secara teknik integral, dapat diketahui dari Tabel 2.

Tabel 2. Data Perhitungan Momen Inersia

\begin{tabular}{cccccc}
\hline No. & Jari-jari $(\mathbf{m})$ & Volume $\left(\mathbf{m}^{\mathbf{3}}\right)$ & $\begin{array}{c}\text { Massa jenis } \\
\left(\mathbf{k g} / \mathbf{m}^{\mathbf{3}}\right)\end{array}$ & $\begin{array}{c}(\boldsymbol{I}) \text { Berbantuan } \\
\text { Tracker }\left(\mathbf{k g . m ^ { 2 }}\right)\end{array}$ & $\begin{array}{c}(\text { I) Integral } \\
\left(\mathbf{k g . m ^ { 2 }}\right)\end{array}$ \\
\hline 1 & $2,4 \times 10^{-3}$ & $217,03 \times 10^{-8}$ & 35340,74 & $2,208 \times 10^{-8}$ & $2,209 \times 10^{-8}$ \\
\hline 2 & $3,7 \times 10^{-3}$ & $515,83 \times 10^{-8}$ & 14869,24 & $3,02 \times 10^{-7}$ & $2,754 \times 10^{-7}$ \\
\hline 3 & $5,6 \times 10^{-3}$ & $1181,64 \times 10^{-8}$ & 6490,98 & $5,25 \times 10^{-6}$ & $5,25 \times 10^{-6}$ \\
\hline
\end{tabular}

Dari data yang terdapat dalam Tabel 2 dapat diketahui bahwa penentuan nilai momen inersia dengan perhitungan berbantuan Tracker dan integral mempunyai hasil yang hampir sama.

Secara keseluruhan hasilnya menyatakan bahwa semakin besar jari-jari suatu benda maka semakin besar pula momen inersia, maka hal ini membuktikan teori mengenai momen inersia yang menyatakan bahwa momen inersia sebanding dengan kuadrat jarak benda (Tipler, 1998).

Dari Tabel 2 dapat dilihat bahwa, semakin besar nilai dari kuadrat jari-jari maka semakin besar juga nilai momen inersianya. Ketika silinder memiliki jari-jari senilai $2,4 \times 10^{-3} \mathrm{~m}$ (jari-jari terkecil) sehingga diperoleh momen inersianya berada pada nilai terkecil yaitu $2,028 \times 10^{-8} \mathrm{~kg} \cdot \mathrm{m}^{2}$. Kemudian pada saat silinder memiliki jarijari senilai 5,6 x 10 $10^{-3}$ meter (jari-jari terbesar) sehingga diperoleh momen inersianya berada pada nilai terbesar yaitu $5,25 \times 10^{-6} \mathrm{~kg} \cdot \mathrm{m}^{2}$.

Dari perhitungan momen inersia menggunakan integral, hasilnya sangat sesuai dengan teori yang ada. Ketika massa menjadi variabel tetap dan jari-jari menjadi variabel yang berubah, nilai jari-jari menjadi sangat berpengaruh terhadap nilai dari momen inersia. Hasil pengolahan data dan teori menunjukan bahwa kuadrat jari-jari dan nilai momen inersia berbanding lurus (Giancoli, 2013).

Hasil pengolahan data juga membuktikan konsep hukum II Newton tentang gerak rotasi yang menyatakan bahwa momen inersia adalah sifat fisis yang mewakili gerak rotasi benda berotasi (Jumini, 2013).

Penentuan momen inersia baik dengan berbantukan aplikasi Tracker dan teknik integral yang dihasilkan dari teorema sumbu 
sejajar akan mendapatkan nilai momen inersia yang hampir sama. Munculnya selisih dari hasil tersebut dapat disebabkan oleh beberapa faktor yang di dapat dari hasil analisis ketika melakukan percobaan, yakni dapat disebabkan karena adanya ketidaktelitian pengukuran, kurang teliti dalam proses Tracker sehingga menyebabkan data kurang akurat.

Selain itu adanya sebab fisis yang alamiah juga mempengaruhi ketika proses eksperimen, yaitu adanya faktor lain yang mempengaruhi gerak rotasi benda, seperti gaya gravitasi bumi, energi potensial benda ketika benda melakukan gerak, kecepatan benda yang tidak konstan, sehingga berdampak pada proses Tracker.

Proses tracker akan akurat ketika gerak benda yang diamati konstan dan arah bola bergerak juga tetap lurus walaupun dalam keadaan gerak menggelinding. Hal itu sejalan dengan hasil penelitian Setyawan (2013) yang menyatakan bahwa gerak benda yang menggelinding harus konstan, hal ini bertujuan agar data yang dihasilkan mempunyai tingkat akurat dan ketelitian yang tinggi.

Hal itu juga diperkuat dengan pendapat Halliday, Resnick, \& Walker (2010) bahwa gerak memiliki sifat umum yaitu berupa asumsi dimana objek bergerak dapat berupa partikel dan setiap bagian bergerak dalam arah dan kecepatan yang sama berada disepanjang garis lurus baik vertikal, horizontal maupun miring.

\section{SIMPULAN}

Dari hasil penelitian dan pengolahan data diperoleh nilai momen inersia dari pengolahan data tracker yaitu $2,208 \times 10^{-8}$ kg. $\mathrm{m}^{2}$ dengan jari-jari $2,4 \times 10^{-3} \mathrm{~m}, 3,02 \times 10^{-}$ ${ }^{7} \mathrm{~kg} \cdot \mathrm{m}^{2}$ dengan jari-jari $3,7 \times 10^{-3} \mathrm{~m}, 5,25 \mathrm{x}$ $10^{-6} \mathrm{~kg} \cdot \mathrm{m}^{2}$ dengan jari-jari $5,6 \times 10^{-3} \mathrm{~m}$. Sedangkan secara perhitungan menggunakan teknik integral yaitu $2,209 \times 10^{-8} \mathrm{~kg} . \mathrm{m}^{2}$ dengan jari-jari $2,4 \times 10^{-3} \mathrm{~m}, 2,754 \times 10^{-7}$ kg. $\mathrm{m}^{2}$ dengan jari-jari $3,7 \times 10^{-3} \mathrm{~m}, 5,25 \times 10^{-}$ ${ }^{6} \mathrm{~kg} . \mathrm{m}^{2}$ dengan jari-jari $5,6 \times 10^{-3} \mathrm{~m}$. Kedua metode tersebut menunjukkkan hasil momen inersia yang hampir sama.

\section{DAFTAR PUSTAKA}

Banjarnahor, H. (2012). Sistem Pengukuran Momen Inersia Benda Pejal Dengan Metode Osilasi Harmonik Berbasis Mikrokontroler. (pp. 1-29). Depok: Universitas Indonesia.

Giancoli, D. C. (2013). Fisika Edisi Ketujuh Jilid 1. Jakarta: Erlangga.

Hajderi, A. (2012). Case Study on Determination of Inertia Moments of Details with Complex Shapes. Basic \& Applied Sciences IJBAS-IJENS , 12 (6), 241-244.

Halliday, D., Resnick, R., \& Walker, J. (2010). Fisika Dasar 1 Edisi 7 Jilid 1. Jakarta: Erlangga.

Hara, Y. (2012). Moment of Inertia Dependence of Vertical AxisWind Turbines in. International Journal of Rotating Machinery , 1-13.

Juansyah, A. (2015). Pengembangan Aplikasi Child Tracker Berbasis Assisted Global Positioning System (A-GPS) Dengan Platform Android. Komputa , 1 (1), 1-8.

Jumini, S. (2013). Pengaruh Perbedaan Panjang Poros Suatu Benda Teradap Kecepatan Sudut Putar. 4, p. 133=138. Salatiga: Prosiding Seminar Nasional Sains dan pendidikan Sains VIII.

Krishnan, R. H. (2016). Estimation Of Mass Moment Of Inertia of Human. Engineering Science and Technology, 11 (2), 166-176.

Kuntoro P., T., \& Murdaka Eka J., B. (2009). Fisika Dasar. Yogyakarta: CV Andi Offset.

Mochlas, A. J. (2016). Kit Percobaan Untuk Menentukan Momen Inersia Benda Tegar. Jurnal Inovasi Fisika Indonesia , 5 (3), $1-5$.

Riswanto. (2014). Penentuan Koefisien Momen Inersia Bola Pejal Melalui Video Gerak. Pertemuan Ilmiah XXVIII HFI Jateng \& DIY (p. 31). Yogyakarta: HFI. 
Jurnal Pendidikan Fisika dan Keilmuan, 4 (1), 2018 - 47

Muhammad Minan Chusni, Muhammad Ferdinan Rizaldi, Santi Nurlaela, Siti Nursetia, Wawat Susilawati

Rivia, N. (2016). Pembuatan Alat Ukur

Momen Inersia Benda Digital

Menggunakan Sensor Optocoupler.

Pillar Of Physics , 8, 81-88.

Sahala S., S. (2013). Penentuan Inersia Benda Tegar Dengan Bandul Fisis. PendidikaMatematika Dan IPA , 4 (2), 36-42.

Setyawan, D. N. (2017). Pengembangan Pembelajaran Berbasis Saintifik pada Materi Dinamika Rotasi dan Kesetimbangan Benda Tegar untuk Meningkatkan Kemampuan Berpikir Kritis dan Komunikasi Verbal Siswa SMA. Jurnal Penelitian Pembelajaran Fisika , 8 (1), 14-25.
Yusuf, K. (2015). Penentuan Momen Inersia dengan Video Analisis. 1, pp. 1-6. Wonosobo: SNFPF.

Zafar, H. (2012). measurement rotational inertia ( ring anf disc) with high percentage accuracy Using rotary motion sensor and three step pulley. International journal of aplied science and technology , 2 (2), 110113.

Zhang, C. (2014). Moment Of Inertia Measurement Based On Displacement Sensor. Bio Technology An Indian Journal , 10 (13), 7501-7505.

Tipler. (1998). Fisika Edisi Ketiga Jilid 1. Jakarta: Erlangga.

Tristiono, T. (2011). Luas Daerah, Titik Berat Dan Momen Inersia Polar Kardioda. Agri-tek, 12 (1), 44-49. 